\title{
Synthesis and Properties of Donor-acceptor-type Polymers Comprising Alkoxy-substituted Bithiophene Units
}

\author{
Ichiro Imae*, Naofumi Tada, and Yutaka Harima \\ Department of Applied Chemistry, Graduate School of Engineering, Hiroshima \\ University, 1-4-1 Kagamiyama, Higashi-Hiroshima, Hiroshima 739-8527, Japan \\ *imae@hiroshima-u.ac.jp
}

Two donor-acceptor-type conjugated polymers comprising alkoxy-substituted bithiophenes were synthesized by both direct $\mathrm{C}-\mathrm{H}$ arylation polymerization and Stille-type polycondensation. Although these polymers contain the same components, i.e. two alkoxythiophene moieties and one benzothiadiazole moiety in a repeating unit, their optical and electrochemical properties were clearly different owing to their different regioregularities. Keywords: Donor-acceptor structure, Direct C-H arylation polymerization, Substituent effect, Regioregularity, Optical absorption, Oxidation potential

\section{Introduction}

Alternating donor-acceptor-type conjugated polymers (D-A-type polymers) comprising electron-rich donor and electron-poor acceptor units have attracted considerable research attention because they constitute one of the most successful types of low-bandgap polymers [1-3]. Their low bandgaps result from donor-to-acceptor intramolecular charge transfer (ICT) [4,5]. Furthermore, this low bandgap endows D-A-type polymers with the ability to absorb light in both the visible and near-infrared regions, allowing them to be widely applied to optoelectronic materials used in electrochromic windows [6,7], optical filters and lasers [8], biosensors $[9,10]$, photothermal therapy [11,12], light-emitting diodes [13], thin-film transistors [14], and organic photovoltaics [15-19]. However, although extensive research effort has been committed to controlling the electronic properties of D-A-type polymers by changing the chemical structures of the D and A units, the systematic tuning of these properties has not been well investigated.

We have previously reported the synthesis of a series of oligothiophenes with well-defined structures and investigated their optical, electrochemical, and electrical properties [20-24]. These studies revealed that the electronic properties of oligothiophenes can be tuned easily and systematically by adjusting their chemical structures. For example, increasing the chain lengths of the oligothiophenes and introducing ethylenedioxy groups at the $\beta$-position of the thiophene rings causes a red-shift in the optical absorption bands and a negative shift in the oxidation potentials [22].

Using this ability to systematically tune the electronic properties of oligothiophenes, we have recently employed alkoxy-substituted

(a)

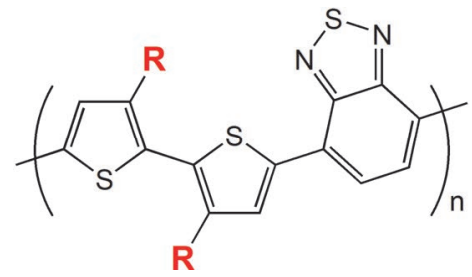

(b)

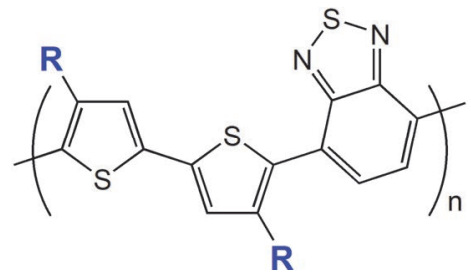

Fig. 1. Chemical structures of D-A polymers comprising bithiophenes with different regioregularities; (a) head-tohead and (b) tail-to-tail structures. 
oligothiophenes with well-defined structures as D units in D-A-type polymers [25] and D-A-D-type molecules [26], and found that the introduction of alkoxy groups can be used to control their electronic properties, as well as their thermal and photovoltaic properties.

In this study, to further investigate the effects of alkoxy-substituents on oligothiophene units, we have synthesized two different D-A-type polymers composed of alkoxy-substituted bithiophenes with distinct regioregularities (head-to-head and tail-totail) and benzothiadiazole (BTD) units (Fig. 1, R = $\left.\mathrm{OC}_{5} \mathrm{H}_{11}\right)$. The optical and electrochemical properties of the two polymers, and the relationship between those properties and the regioregularities of the alkoxy substituents, were investigated.

\section{Experimental}

\subsection{Materials and instrumentation}

$$
\text { Palladium acetate }\left(\mathrm{Pd}(\mathrm{OAc})_{2}\right) \text {, }
$$

bis(dibenzylideneacetone)palladium $\quad\left(\mathrm{Pd}(\mathrm{dba})_{2}\right)$, tetrakis(triphenylphosphine)palladium $\left(\mathrm{Pd}\left(\mathrm{PPh}_{3}\right)_{4}\right)$, tris $\left(o\right.$-methoxyphenyl)phosphine $\quad\left(\mathrm{P}(o-\mathrm{MeOPh})_{3}\right)$, tetrabutylammonium bromide (TBAB), potassium acetate (KOAc), pivalic acid (PivOH), Nbromosuccinimide (NBS), 3-bromothiophene, and 4,7-dibromo-2,1,3-benzothiadiazole (5) were purchased from Wako, Tokyo Chemical Industries (TCI), and Aldrich, and used without purification. Tetrabutylammonium perchlorate (TBAP) and tetraethylammonium perchlorate (TEAP) were purchased from TCI and Nacalai Tesque, respectively, and purified by recrystallization from ethanol. Solvents for syntheses and the measurement of optical and electrochemical properties were purified by standard methods and used immediately after purification.

Microwave reactions were conducted using a Monowave 300 (Anton Paar). ${ }^{1} \mathrm{H}$ NMR spectra were recorded on a $500-\mathrm{MHz}$ spectrometer (Varian Inc., NMR System 500) and a $600-\mathrm{MHz}$ spectrometer (JEOL, JNM-ECA-600). The molecular weights of the resulting polymers were measured using a gel permeation chromatography (GPC) system coupled with a UV detector (Shimadzu, SPD-10A). A combination of Shodex KF-801 $(30 \mathrm{~cm}$, exclusion limit, $M_{\mathrm{n}}=1.5 \times 10^{3}$, polystyrene), KF-802 $(30 \mathrm{~cm}$, exclusion limit, $M_{\mathrm{n}}=5.0 \times 10^{3}$, polystyrene), and KF-803L (30 cm, exclusion limit, $M_{\mathrm{n}}=7.0 \times 10^{4}$, polystyrene) columns (linear calibration down to $M_{\mathrm{n}}$ $=100$ ) were used for molecular weight analysis with THF $\left(1.0 \mathrm{~mL} \mathrm{~min}^{-1}\right)$ as an eluent. UV-Vis absorption spectra were obtained on a UV-3150 spectrophotometer (Shimadzu). Cyclic voltammetry (CV) was carried out with a potentiostat/galvanostat (Hokuto Denko, HZ-3000) using a three-electrode system with a Pt spherical working electrode, a Pt wire counter electrode, and a $\mathrm{Ag} / \mathrm{Ag}^{+}$reference electrode. The ferrocene/ferrocenium $\left(\mathrm{Fc} / \mathrm{Fc}^{+}\right)$couple was used as the internal reference for measurements to minimize problems with liquid junction potentials, and all the potentials were calibrated with the $\mathrm{Fc} / \mathrm{Fc}^{+}$redox pair. The HOMO energy $\left(E_{\text {НОмо }}\right)$ was estimated from the onset potential of oxidation ( $E_{\text {ox }}{ }^{\text {onset }}$ ) and by assuming the $\mathrm{Fc} / \mathrm{Fc}^{+}$energy level to be $4.8 \mathrm{eV}$ below the vacuum level [27]. The LUMO energy ( $\left.E_{\mathrm{LUMO}}\right)$ was calculated from $E_{\text {Номо }}$ and the bandgap energies $\left(E_{\mathrm{g}}\right)$ estimated from the band edge of the absorption spectra.

\subsection{Synthesis of monomers}

The synthetic route to the monomers is illustrated in Scheme 1 and the detailed synthetic procedures are given below:

\subsubsection{3-(n-Pentyloxy)thiophene (1)}

3 -(n-Pentyloxy)thiophene was synthesized according to a modified version of a method reported previously [28]. Briefly, sodium (6.50 g, $0.23 \mathrm{~mol})$ was added to $n$-pentanol $(66.1 \mathrm{~g}, 0.75$ mol), which was stirred at room temperature until the sodium disappeared completely. The resultant suspension was evaporated under vacuum to afford a white powder. Under inert atmosphere, DMF (50 $\mathrm{mL}$ ) was added to the powder, and 3bromothiophene $(24.5 \mathrm{~g}, 0.15 \mathrm{~mol})$ was then added to the reaction mixture. After $5 \mathrm{~min}$, cuprous bromide $(\mathrm{Cu}(\mathrm{I}) \mathrm{Br}, 2.50 \mathrm{~g}, 15 \mathrm{mmol})$ was added, and the reaction was stirred for $12 \mathrm{~h}$ at $100{ }^{\circ} \mathrm{C}$. After the reaction temperature dropped to room temperature, the solution was poured into distilled water $(1 \mathrm{~L})$ and extracted with $\mathrm{CH}_{2} \mathrm{Cl}_{2}$. The organic extract was washed with distilled water and dried over anhydrous $\mathrm{Na}_{2} \mathrm{SO}_{4}$. The solvent was then removed by rotary evaporation. The crude product was purified by column chromatography $\left(\mathrm{SiO}_{2}, n\right.$ hexane/ $\left.\mathrm{CH}_{2} \mathrm{Cl}_{2}(8: 1, v / v)\right)$ to afford $\mathbf{1}$ as a paleyellow liquid (24.0 g, $0.14 \mathrm{~mol}$, yield $88 \%$ ).

${ }^{1} \mathrm{H}$ NMR $\left(500 \mathrm{MHz},\left(\mathrm{CD}_{3}\right)_{2} \mathrm{CO}, \delta, \mathrm{ppm}\right): 0.91(\mathrm{t}$, $\left.J=7.2 \mathrm{~Hz}, 3 \mathrm{H}, \quad \mathrm{CH}_{3}\right), 1.32-1.48(\mathrm{~m}, 4 \mathrm{H}$, $\left.\left(\mathrm{CH}_{2}\right)_{2} \mathrm{CH}_{3}\right), 1.70-1.78\left(\mathrm{~m}, 2 \mathrm{H}, \mathrm{OCH}_{2} \mathrm{CH}_{2}\right), 3.96(\mathrm{t}$, $\left.J=6.5 \mathrm{~Hz}, 2 \mathrm{H}, \mathrm{OCH}_{2}\right), 6.42(\mathrm{dd}, J=1.5,3.1 \mathrm{~Hz}$, $1 \mathrm{H}$, thienyl-H), $6.72(\mathrm{dd}, J=1.5,5.3 \mathrm{~Hz}, 1 \mathrm{H}$, thienyl- $\boldsymbol{H}), 7.29(\mathrm{dd}, J=3.1,5.3 \mathrm{~Hz}, 1 \mathrm{H}$, thienyl- $\boldsymbol{H})$ 

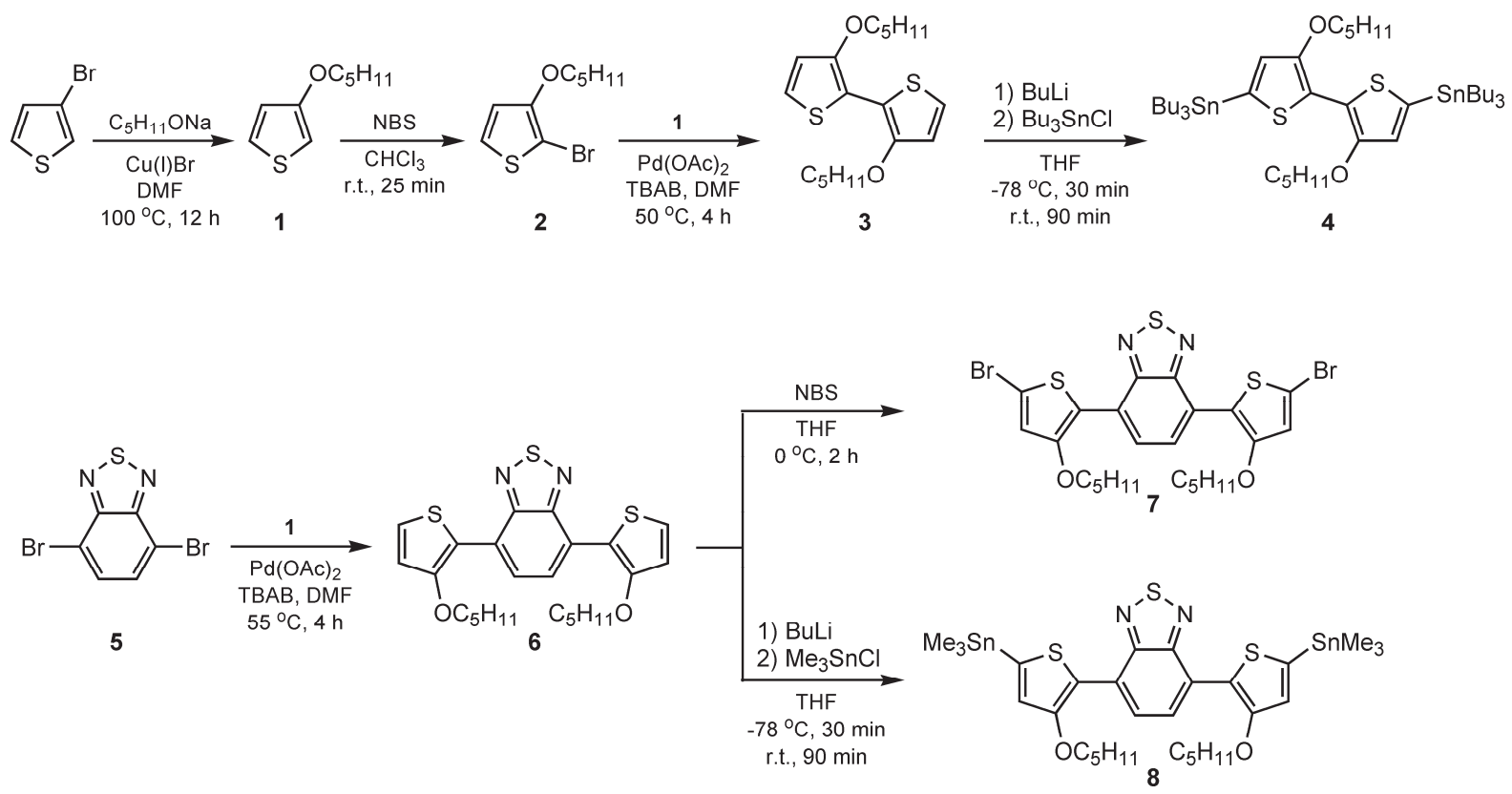

Scheme 1 . Synthetic route to the monomers used in this study.

\subsubsection{2-Bromo-3-(n-pentyloxy)thiophene (2)}

To a $\mathrm{CHCl}_{3}(200 \mathrm{~mL})$ solution of $\mathbf{1}(2.55 \mathrm{~g}, 15$ mmol), NBS (2.67 g, $15 \mathrm{mmol})$ was slowly added in the dark. The reaction mixture was stirred in the dark for $25 \mathrm{~min}$ and poured into water then extracted twice with $\mathrm{CHCl}_{3}$. The organic extracts were washed with sat. aq. $\mathrm{Na}_{2} \mathrm{CO}_{3}$ and water and dried over anhydrous $\mathrm{Na}_{2} \mathrm{SO}_{4}$. The solvent was evaporated, and the residue was purified by column chromatography $\left(\mathrm{SiO}_{2}, n\right.$-hexane/ $\left.\mathrm{CH}_{2} \mathrm{Cl}_{2}(8: 1, v / v)\right)$ to afford a yellow liquid $(3.66 \mathrm{~g}, 15 \mathrm{mmol}$, yield $98 \%$ ).

${ }^{1} \mathrm{H}$ NMR (500 MHz, $\left.\left(\mathrm{CD}_{3}\right)_{2} \mathrm{CO}, \delta, \mathrm{ppm}\right): 0.91(\mathrm{t}$, $\left.J=7.2 \mathrm{~Hz}, 3 \mathrm{H}, \quad \mathrm{CH}_{3}\right), 1.34-1.46(\mathrm{~m}, 4 \mathrm{H}$, $\left.\left(\mathrm{CH}_{2}\right)_{2} \mathrm{CH}_{3}\right), 1.72\left(\mathrm{tt}, J=7.0 \mathrm{~Hz}, 2 \mathrm{H}, \mathrm{OCH}_{2} \mathrm{CH}_{2}\right)$, $4.07\left(\mathrm{t}, J=6.5 \mathrm{~Hz}, 2 \mathrm{H}, \mathrm{OCH}_{2}\right), 6.95(\mathrm{~d}, J=6.0 \mathrm{~Hz}$, $1 \mathrm{H}$, thienyl- $\boldsymbol{H}), 7.46(\mathrm{~d}, J=6.0 \mathrm{~Hz}, 1 \mathrm{H}$, thienyl- $\boldsymbol{H})$.

\subsubsection{3,3'-Bis(n-pentyloxy)-2,2'-bithiophene (3)}

A DMF $(30 \mathrm{~mL})$ solution containing $1(5.11 \mathrm{~g}, 30$ mmol), 2 (7.32 g, $29 \mathrm{mmol}), \mathrm{Pd}(\mathrm{OAc})_{2}(337 \mathrm{mg}, 1.5$ $\mathrm{mmol})$, TBAB ( $9.67 \mathrm{~g}, 30 \mathrm{mmol})$, and KOAc (6.86 $\mathrm{g}, 70 \mathrm{mmol}$ ) was stirred at $50{ }^{\circ} \mathrm{C}$ for $4 \mathrm{~h}$ and then poured into distilled water $(1 \mathrm{~L})$ and extracted with $\mathrm{CH}_{2} \mathrm{Cl}_{2}$. The organic extract was washed with distilled water and dried over $\mathrm{Na}_{2} \mathrm{SO}_{4}$. The solvent was then evaporated and the residue was purified by column chromatography $\left(\mathrm{SiO}_{2}, n\right.$-hexane $/ \mathrm{CH}_{2} \mathrm{Cl}_{2}$ $(5: 1, v / v))$ followed by recrystallization from methanol to afford a pale-yellow solid (997 mg, 3.0 mmol, yield $10 \%$ ).

${ }^{1} \mathrm{H}$ NMR $\left(500 \mathrm{MHz},\left(\mathrm{CD}_{3}\right)_{2} \mathrm{CO}, \delta, \mathrm{ppm}\right): 0.92(\mathrm{t}$, $\left.J=7.3 \mathrm{~Hz}, 6 \mathrm{H}, \mathbf{C} \boldsymbol{H}_{3}\right), 1.34-1.43(\mathrm{~m}, 8 \mathrm{H}$,
$\left.\left(\mathrm{CH}_{2}\right)_{2} \mathrm{CH}_{3}\right), 1.83\left(\mathrm{tt}, J=7.1 \mathrm{~Hz}, 4 \mathrm{H}, \mathrm{OCH}_{2} \mathrm{CH}_{2}\right)$, $4.13\left(\mathrm{t}, J=6.4 \mathrm{~Hz}, 4 \mathrm{H}, \mathrm{OCH}_{2}\right), 6.97(\mathrm{~d}, J=5.6 \mathrm{~Hz}$, $2 \mathrm{H}$, thienyl- $\boldsymbol{H}), 7.23(\mathrm{~d}, J=5.6 \mathrm{~Hz}, 2 \mathrm{H}$, thienyl- $\boldsymbol{H})$.

2.2.4. 4,7-Bis(3-(n-pentyloxy)thiophen-2-yl)-2,1,3benzothiadiazole (6)

A DMF $(30 \mathrm{~mL})$ solution containing $1(2.56 \mathrm{~g}, 15$ $\mathrm{mmol}), 5$ (1.48 g, $5.0 \mathrm{mmol}), \mathrm{Pd}(\mathrm{OAc})_{2}(50.0 \mathrm{mg}$, $0.22 \mathrm{mmol})$, TBAB (4.84 g, $15 \mathrm{mmol})$, and KOAc (3.43 g, $35 \mathrm{mmol}$ ) was stirred at $55^{\circ} \mathrm{C}$ for $4 \mathrm{~h}$ and then poured into distilled water $(1 \mathrm{~L})$ and extracted with $\mathrm{CH}_{2} \mathrm{Cl}_{2}$. The organic extract was washed with distilled water and dried over anhydrous $\mathrm{Na}_{2} \mathrm{SO}_{4}$. The solvent was then evaporated and the residue was purified by column chromatography $\left(\mathrm{SiO}_{2}, n\right.$ hexane $\left./ \mathrm{CH}_{2} \mathrm{Cl}_{2}(3: 2, v / v)\right)$ to afford a red solid $(1.95$ g, $4.1 \mathrm{mmol}$, yield 83\%).

${ }^{1} \mathrm{H}$ NMR (500 MHz, $\left.\left(\mathrm{CD}_{3}\right)_{2} \mathrm{CO}, \delta, \mathrm{ppm}\right): 0.94(\mathrm{t}$, $\left.J=7.3 \mathrm{~Hz}, 6 \mathrm{H}, \mathrm{CH}_{3}\right), 1.39-1.47\left(\mathrm{~m}, 4 \mathrm{H}, \mathrm{CH}_{2} \mathrm{CH}_{3}\right)$, $1.54\left(\mathrm{tt}, J=2.5,3.9 \mathrm{~Hz}, 4 \mathrm{H}, \mathrm{CH}_{2} \mathrm{CH}_{2} \mathrm{CH}_{3}\right), 1.85-$ $1.92\left(\mathrm{~m}, 4 \mathrm{H}, \mathrm{OCH}_{2} \mathrm{CH}_{2}\right), 4.27(\mathrm{t}, J=6.4 \mathrm{~Hz}, 4 \mathrm{H}$, $\left.\mathrm{OCH}_{2}\right), 7.17(\mathrm{~d}, J=5.6 \mathrm{~Hz}, 2 \mathrm{H}$, thienyl- $\boldsymbol{H}), 7.58(\mathrm{~d}$, $J=5.6 \mathrm{~Hz}, 2 \mathrm{H}$, thienyl-H), 8.61 (s, 2H, BTD- $\boldsymbol{H}$ ).

\subsubsection{4,7-Bis(5-bromo-3-(n-pentyloxy)thiophen-2-} yl)-2,1,3-benzothiadiazole (7)

To a THF $(30 \mathrm{~mL})$ solution of $6(713 \mathrm{mg}, 1.5$ mmol) was slowly added NBS (522 mg, $2.9 \mathrm{mmol}$ ) at $0{ }^{\circ} \mathrm{C}$ in the dark. The reaction mixture was stirred at $0{ }^{\circ} \mathrm{C}$ in the dark for $2 \mathrm{~h}$ and then poured into water and extracted twice with $\mathrm{CH}_{2} \mathrm{Cl}_{2}$. The organic extracts were washed with sat. aq. $\mathrm{Na}_{2} \mathrm{CO}_{3}$ and water and then dried over anhydrous $\mathrm{Na}_{2} \mathrm{SO}_{4}$. The 
solvent was evaporated, and the residue was purified by column chromatography $\left(\mathrm{SiO}_{2}, n\right.$ hexane $\left./ \mathrm{CH}_{2} \mathrm{Cl}_{2}(3: 1, v / v)\right)$ to afford a red solid (830 $\mathrm{mg}, 1.3 \mathrm{mmol}$, yield $87 \%$ ).

${ }^{1} \mathrm{H}$ NMR (500 MHz, $\left.\left(\mathrm{CD}_{3}\right)_{2} \mathrm{CO}, \delta, \mathrm{ppm}\right): 0.95(\mathrm{t}$, $\left.J=7.3 \mathrm{~Hz}, 6 \mathrm{H}, \mathrm{CH}_{3}\right), 1.41-1.48\left(\mathrm{~m}, 4 \mathrm{H}, \mathrm{CH}_{2} \mathrm{CH}_{3}\right)$, 1.54 (tt, $\left.J=2.7,3.8 \mathrm{~Hz}, 4 \mathrm{H}, \mathrm{CH}_{2} \mathrm{CH}_{2} \mathrm{CH}_{3}\right), 1.86-$ $1.93\left(\mathrm{~m}, 4 \mathrm{H}, \mathrm{OCH}_{2} \mathrm{CH}_{2}\right), 4.29(\mathrm{t}, J=6.4 \mathrm{~Hz}, 4 \mathrm{H}$, $\left.\mathrm{OCH}_{2}\right), 7.30$ (s, 2H, thienyl-H), 8.58 (s, 2H, BTD$\boldsymbol{H})$.

\subsection{Polymerization}

Synthesis of the target polymers, $h \boldsymbol{h}$ 2T-BTD and $t t 2 T-B T D$, where $h \boldsymbol{h}$ and $\boldsymbol{t} t$ indicate head-to-head and tail-to-tail, respectively, were attempted using direct $\mathrm{C}-\mathrm{H}$ arylation polymerization (DArP) and polycondensation via Stille coupling (Scheme 2). Details of the respective procedures are given below:
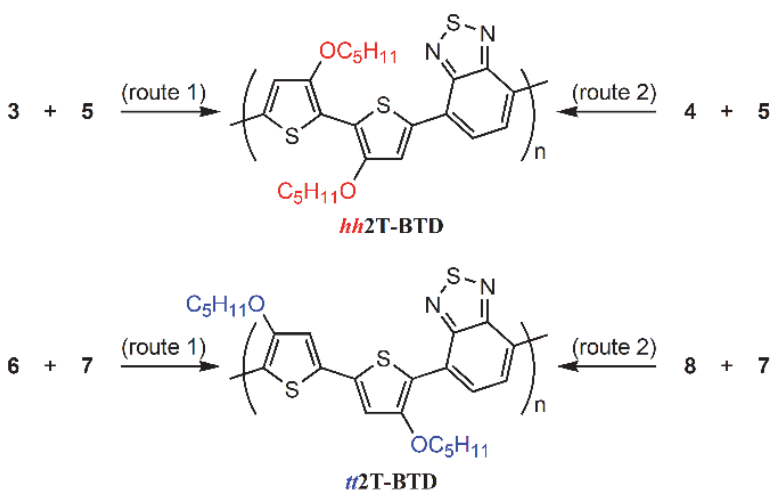

Scheme 2. Synthesis of $h \boldsymbol{h} \mathbf{2 T - B T D}$ and $t \boldsymbol{t 2 T - B T D .}$

2.3.1. Poly[(2,1,3-benzothiadiazol-4,7-diyl)-(3,3'bis(n-pentyloxy)-2,2' -bithiophene-5,5'-diyl)]

(hh2T-BTD) (route 1, DArP)

$\left.\mathrm{Pd}(\mathrm{dba})_{2}(8.6 \mathrm{mg}, 10 \mathrm{~mol} \%), \mathrm{P}(o-\mathrm{MeOPh})_{3}\right)(5$ $\mathrm{mg}, 10 \mathrm{~mol} \%$ ), cesium carbonate (146 $\mathrm{mg}, 0.45$ $\mathrm{mmol}$ ), PivOH (46 mg, $0.45 \mathrm{mmol}$ ), 3 (102 mg, 0.30 $\mathrm{mmol})$, and 5 ( $88.8 \mathrm{mg}, 0.30 \mathrm{mmol})$ were placed in a $10-\mathrm{mL}$ microwave vessel with a magnetic stir bar. THF $(3 \mathrm{~mL})$ was added and the resulting solution was bubbled with dry nitrogen to remove dissolved oxygen. The vessel was then sealed and placed in the microwave reactor. The solution was heated at $100^{\circ} \mathrm{C}$ for $1 \mathrm{~h}$, after which the mixture was poured into methanol. The resultant precipitate was washed with methanol and dissolved in $\mathrm{CHCl}_{3}$. A metal scavenger (SiliaMetS DMT, SiliCycle Inc.) was added to the solution to remove palladium derivatives and the mixture was stirred for $3 \mathrm{~h}$ at room temperature. After filtration, the solvent was evaporated and the residue was purified by reprecipitation to afford a black solid.

${ }^{1} \mathrm{H}$ NMR (600 MHz, THF- $d_{8}, \delta$, ppm): 0.95-1.08 (br, 6H, $\left.\mathrm{CH}_{3}\right), 1.44-1.63$ (br, 8H, $\left.\left(\mathrm{CH}_{2}\right)_{2} \mathrm{CH}_{3}\right), 1.99-$ 2.10 (br, 4H, $\left.\mathrm{OCH}_{2} \mathrm{CH}_{2}\right), 4.31-4.42\left(\mathrm{br}, 4 \mathrm{H}, \mathrm{OCH}_{2}\right.$ ), 7.85-7.94 (br, $2 \mathrm{H}$, thienyl- $\boldsymbol{H}$ ), 8.13-8.20 (br, $2 \mathrm{H}$, BTD- $\boldsymbol{H})$.

2.3.2. Poly[(2,1,3-benzothiadiazol-4,7-diyl)-(3,3'bis(n-pentyloxy)-2,2'-bithiophene-5,5'-diyl)]

(hh2T-BTD) (route 2, Stille)

To a solution of 3 (102 $\mathrm{mg}, 0.3 \mathrm{mmol})$ in THF (6 $\mathrm{mL})$ at $-78{ }^{\circ} \mathrm{C}$ was added $0.5 \mathrm{~mL}(0.8 \mathrm{mmol})$ of $n$ butyllithium (1.6 $\mathrm{M}$ in $n$-hexane) using a syringe. The mixture was stirred at $-78^{\circ} \mathrm{C}$ for $2 \mathrm{~h}$. Tri $(n-$ butyl)tin chloride ( $326 \mathrm{mg}, 1.0 \mathrm{mmol}$ ) was added to the solution, and the resulting mixture was stirred at $-78{ }^{\circ} \mathrm{C}$ for $30 \mathrm{~min}$, warmed to room temperature, and stirred for a further $90 \mathrm{~min}$. The solvent was then removed via rotary evaporation and $n$-hexane was added to the residue. The soluble fraction was extracted by filtration. The compound $\mathbf{4}$ obtained by evaporation of the filtered solution was added to a solution of $\mathrm{Pd}\left(\mathrm{PPh}_{3}\right)_{4}(17.3 \mathrm{mg}, 0.015 \mathrm{mmol})$ and 5 ( $88.8 \mathrm{mg}, 0.30 \mathrm{mmol})$ in DMF (3 mL). The solution was stirred at $80^{\circ} \mathrm{C}$ for $24 \mathrm{~h}$. The mixture was then poured into methanol and the resultant precipitate was washed with methanol.

2.3.3. Poly[(2,1,3-benzothiadiazol-4,7-diyl)-(4,4' bis(n-pentyloxy)-2,2'-bithiophene-5,5'-diyl)] (tt2TBTD) (route 1, DArP)

The polymer $\boldsymbol{t} 2 \mathrm{~T}$-BTD was prepared using $\mathbf{6}$ and 7 by route 1 according to the same procedure as that described for $h h$ 2T-BTD.

${ }^{1} \mathrm{H}$ NMR (600 MHz, THF- $d_{8}, \delta$, ppm): 0.95-1.02 (br, 6H, $\mathrm{CH}_{3}$ ), 1.41-1.65 (br, 8H, $\left.\left(\mathrm{CH}_{2}\right)_{2} \mathrm{CH}_{3}\right), 1.92-$ 2.01 (br, $4 \mathrm{H}, \mathrm{OCH}_{2} \mathrm{CH}_{2}$ ), 4.32-4.37 (br, $4 \mathrm{H}, \mathrm{OCH}_{2}$ ), 7.36-7.38 (br, $2 \mathrm{H}$, thienyl- $\boldsymbol{H}$ ), 8.54-8.68 (br, $2 \mathrm{H}$, BTD- $\boldsymbol{H})$.

2.3.4. Poly $[(2,1,3$-benzothiadiazol-4,7-diyl)-(4,4' bis(n-pentyloxy)-2,2'-bithiophene-5, 5'-diyl)] (tt2TBTD) (route 2, Stille)

Synthesis of $t$ t2T-BTD was attempted by route 2 using 8 and 7 according to the same procedure as that described for $h \boldsymbol{h} \mathbf{2 T}$-BTD, but the desired polymeric material was not obtained.

\section{Results and discussion}

\subsection{Synthesis and characterization}

BTD was adopted as an acceptor unit in this work because it has been well studied as a representative 
acceptor unit in D-A polymers [29-32] and its dibromo-substituted derivative, 4,7-dibromo-2,1,3BTD (5), is commercially available. 3- $(n-$ Pentyloxy)thiophene (1), where one methylene group at the benzyl position of 3-hexylthiophene is replaced with an oxygen, was synthesized by the coupling reaction of 3-bromothiophene and sodium $n$-pentyloxide, which was freshly synthesized by the reaction of $n$-pentanol and sodium, in the presence of $\mathrm{Cu}(\mathrm{I}) \mathrm{Br} \quad$ [28]. 3,3'-Bis(n-pentyloxy)-2,2'bithiophene (3) was synthesized by the direct $\mathrm{C}-\mathrm{H}$ arylation condensation between $\mathbf{1}$ and $\mathbf{2}$. Compound 3 could also be synthesized by the Stille coupling of 2 and 2-(tributylstannyl)-3-(n-pentyloxy)thiophene, but the purification process requires preparative GPC and is not efficient because the crude product contains a lot of impurities that cannot be separated by ordinary silica-gel column chromatography. Because it was difficult to synthesize $4,4^{\prime}$-bis $(n-$ pentyloxy)-2,2'-bithiophene, 4,7-bis(3-(npentyloxy)thiophen-2-yl)-2,1,3-BTD (6) was synthesized as a monomer for preparing $t$ t2T-BTD.

In order to synthesize $h \boldsymbol{h} \mathbf{2 T - B T D}$ and $\boldsymbol{t} t \mathbf{2 T}$-BTD, two different polymerization methods were employed, i.e., DArP (route 1) and polycondensation using Stillecoupling (route 2) (Scheme 2). The molecular weights and polydispersities of the polymers obtained by each method are summarized in Table 1.

Table 1. Molecular weight data for $h \boldsymbol{h} \mathbf{2 T}$-BTD and $t \boldsymbol{t} \mathbf{2 T}$ BTD as prepared by two different routes. ${ }^{\text {a) }}$

\begin{tabular}{ccccc}
\hline Polymer & route $^{\mathrm{b})}$ & $M_{\mathrm{w}} / \mathrm{kDa}$ & $M_{\mathrm{n}} / \mathrm{kDa}$ & $M_{\mathrm{w}} / M_{\mathrm{n}}$ \\
\hline hh2T-BTD & 1 & 1.98 & 1.40 & 1.41 \\
& 2 & 1.13 & 0.38 & 2.97 \\
\multirow{2}{*}{ t2T-BTD } & 1 & 1.60 & 1.05 & 1.52 \\
& 2 & $-\mathrm{c})$ & $-\mathrm{c})$ & $-\mathrm{c})$
\end{tabular}

a) Measured by GPC using polystyrene standard in THF at $40{ }^{\circ} \mathrm{C}$.

b) Route 1: DArP method, route 2: Stille-type coupling.

c) Polymer was not obtained.

The molecular weight of $\boldsymbol{h h 2 T - B T D}$ obtained by route 2 is lower than that by route 1 . In the case of $t$ t $2 \mathrm{~T}$ BTD, route 1 affords a polymer with a similar molecular weight to that in the case of hh2T-BTD, while route 2 does not afford a polymeric compound. The reason for this result is not clear. Possibly, the bisstannyl compounds (4 and 8) are not sufficiently purified by the preparative GPC protocol employed; therefore, the stoichiometry of the proceeding polycondensation step is artificially low, leading to reduced molecular weights of the polymers obtained by route 2 .

The regioregularities of both polymers were characterized by ${ }^{1} \mathrm{H}$ NMR analysis, confirming that they contain single regioregular structures. This result suggests that the synthetic strategies shown in Scheme 2 are suitable for the synthesis of regioregular polymers.

\subsection{Optical properties}

The optical absorption spectra of $h \boldsymbol{h} \mathbf{2 T}-\mathbf{B T D}$ and tt2T-BTD in solution and film states are shown in Fig. 2 and their data are summarized in Table 2. Both polymer solutions present absorption bands at approximately 400 and $600 \mathrm{~nm}$, corresponding to $\pi$ $\pi^{*}$ transition and the ICT bands, respectively [25]. The absorption bands due to $\pi-\pi^{*}$ transitions are observed at the same wavelength region for $h h \mathbf{2 T}$ BTD and tt2T-BTD, while the ICT bands are observed at 668 and $609 \mathrm{~nm}$, respectively. Thus, the ICT bands of the polymer films are red-shifted by 54 and $33 \mathrm{~nm}$ for $h \boldsymbol{h 2 T}$-BTD and tt2T-BTD

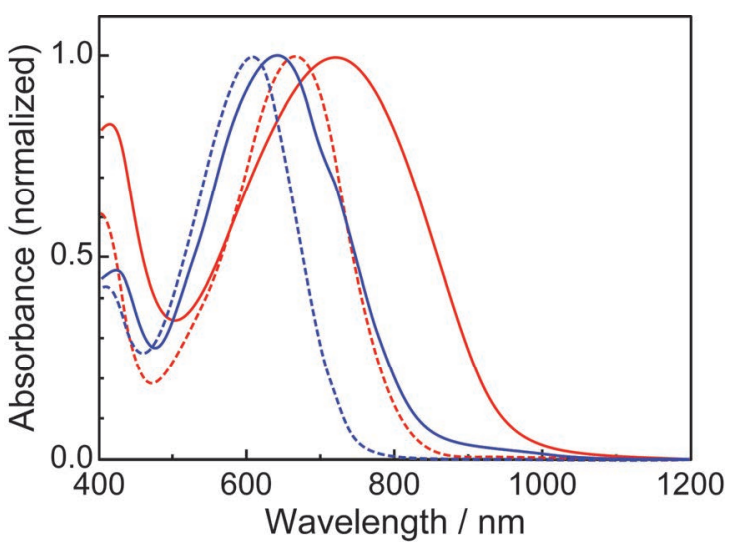

Fig. 2. Absorption spectra of $h h 2 T-B T D$ (red) and $t t 2 T-$ BTD (blue) (solid: film, dashed: $o$-dichlorobenzene solution).

Table 2. Optical absorption properties of the polymers in this study.

\begin{tabular}{|c|c|c|c|c|}
\hline \multirow{2}{*}{ Polymer } & \multirow{2}{*}{$\mathrm{R}$} & \multicolumn{2}{|c|}{$\lambda_{\max } / \mathrm{nm}$} & \multirow{2}{*}{ ref. } \\
\hline & & (solution) & (film) & \\
\hline$h h 2 \mathrm{~T}-\mathrm{BTD}$ & $\mathrm{OC}_{5} \mathrm{H}_{11}$ & $402 / 668^{a)}$ & 412 / 722 & \\
\hline$t t 2 T-B T D$ & $\mathrm{OC}_{5} \mathrm{H}_{11}$ & $408 / 609^{a)}$ & $420 / 642$ & \\
\hline$h h 2 \mathrm{~T}-\mathrm{BTD}-\mathrm{C}_{6}$ & $\mathrm{C}_{6} \mathrm{H}_{13}$ & $330 / 514^{b)}$ & & [33] \\
\hline$h h 2 \mathrm{~T}-\mathrm{BTD}-\mathrm{C} 8$ & $\mathrm{C}_{8} \mathrm{H}_{17}$ & -c) $\left./ 517^{b}\right)$ & -c) $/ 540$ & [34] \\
\hline$t t 2 \mathrm{~T}-\mathrm{BTD}-\mathrm{C}_{8}$ & $\mathrm{C}_{8} \mathrm{H}_{17}$ & -c) $/ 480^{\text {b) }}$ & -c) / 511 & [34] \\
\hline
\end{tabular}


compared to those of polymer solutions.

As references, the optical properties of D-A polymers composed of alkyl-substituted bithiophenes and BTD (Fig. 1, $\mathrm{R}=\mathrm{C}_{\mathrm{n}} \mathrm{H}_{2 \mathrm{n}+1}$, hh2TBTD-C $_{6}(\mathrm{n}=6), \boldsymbol{h h 2 T - B T D - C _ { 8 }}(\mathrm{n}=8), \boldsymbol{t t 2 T - B T D -}$ $\left.\mathbf{C}_{\mathbf{8}}(\mathrm{n}=8)\right)$ are listed in Table 2. The ICT bands are significantly red-shifted by simply replacing the methylene groups at the benzyl position of the alkyl side chains with the oxygen groups. The red-shift due to replacement of the benzyl-methylene groups with the oxygen groups is in good agreement with the results of our previous study on D-A-D-type small molecules [26]. The red-shift of ICT bands due to differences in regioregularity has also been confirmed in the case of alkyl-substituted derivatives, but the degree of the red-shift was much smaller than that in the current case [34].

\subsection{Electrochemical properties}

CV analyses of $h h 2 T-B T D$ and $t$ 2T-BTD were performed to investigate their electrochemical properties. The $\mathrm{CV}$ curves of their dichloromethane solutions are shown in Fig. 3(a). The CV trace of

(a)

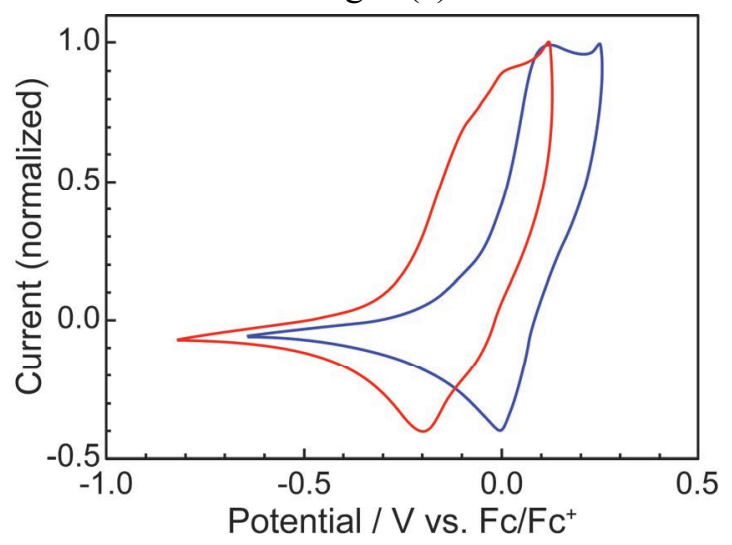

(b)

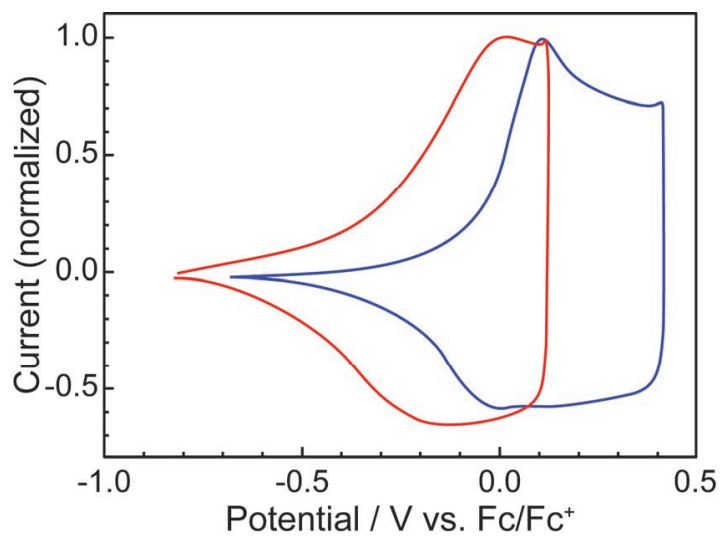

Fig. 3. Cyclic voltammograms of $h \boldsymbol{h 2 T - B T D}$ (red) and tt2T-BTD (blue) in (a) solution and (b) film (solvent: (a) dichloromethane, (b) acetonitrile; electrolyte: (a) $0.1 \mathrm{M}$ TBAP, (b) $0.1 \mathrm{M}$ TEAP; scan rate: (a) $100 \mathrm{mV} \mathrm{sec}^{-1}$, (b) $50 \mathrm{mV} \mathrm{sec}^{-1}$.
tt2T-BTD presents an anodic peak ascribable to the oxidation at $0.12 \mathrm{~V}$ vs. $\mathrm{Fc} / \mathrm{Fc}^{+}$and a corresponding cathodic peak as a result of the reduction of the oxidized tt2T-BTD at $-0.01 \mathrm{~V}$ vs. $\mathrm{Fc} / \mathrm{Fc}^{+}$. Conversely, the corresponding peaks for $h h \mathbf{2 T}$ BTD are observed at more negative potentials than those of $t$ t2T-BTD. The CV curves of both polymer films are broader than those in solution, but the redox potential of $h h \mathbf{2 T}$-BTD is still more negative than that of t2T-BTD (Fig. 3(b)).

The HOMO energy levels $\left(E_{\text {HOMO }}\right)$ are -4.39 and $-4.67 \mathrm{eV}$ for $\boldsymbol{h} \boldsymbol{h} \mathbf{2 T}-\mathrm{BTD}$ and $t \boldsymbol{t 2 T}$-BTD, respectively, as revealed by substituting the onset potentials of oxidation $\left(E_{\mathrm{ox}}{ }^{\text {onset }}\right)$ in the $\mathrm{CV}$ curves of the polymer films into the relationship $E_{\mathrm{HOMO}}=-e\left(E_{\mathrm{ox}}{ }^{\text {onset }}+4.80\right)$ [27]. The LUMO energy levels ( $\left.E_{\mathrm{LUMO}}\right)$ are calculated to be -3.07 and $-3.17 \mathrm{eV}$ for $h h 2 \mathrm{~T}-\mathrm{BTD}$ and $t$ 2T-BTD, respectively, from $E_{\text {НОМо }}$ and the bandgap energy $\left(E_{\mathrm{g}}\right)$ values estimated from the band edges of the absorption spectra. The difference in the regioregularity of the alkoxy substituents on the bithiophene unit affects the HOMO energy levels more strongly than the LUMO levels. The HOMO level of the alkyl-substituted derivative $h \boldsymbol{h} \mathbf{2 T}$-BTD$\mathbf{C}_{6}$ has been reported to be around $-5.4 \mathrm{eV}[35,36]$, which is a much more negative energy level than that of $h \boldsymbol{h} \mathbf{2 T - B T D}$. This result suggests that the introduction of alkoxy groups enhances the electron-donating nature of D-A polymers.

\subsection{Theoretical calculations}

To further investigate the electronic properties of the polymers, density functional theory (DFT) calculations were carried out using Gaussian 09 software and the Becke three-parameter hybrid functional combined with the Lee-Yang-Parr correlation functional (B3LYP) with a polarized 6$31 \mathrm{G}(\mathrm{d})$ basis set [37]. In order to reduce the calculation time, a simplification was adopted by choosing one repeating unit. The optimized molecular geometries were determined as the minimum-energy conformations by vibrational calculations at the same level. The optimized molecular geometries of $h \boldsymbol{h} \mathbf{2 T - B T D}$ and $t \boldsymbol{t 2 T - B T D}$ are shown in Fig. 4. In the case of t2T-BTD, all aromatic rings in the bithiophene and BTD moieties are twisted and their dihedral angles are $44^{\circ}$ between the thiophene and a BTD units and $21^{\circ}$ between two thiophene units. Conversely, $h$ h2TBTD has a planar structure throughout the molecule.

Similar results have been observed in the case of alkyl-substituted derivatives [34]. In that previous report, the difference in the dihedral angles between 
the thiophene and the BTD units is rationalized in terms of the different steric hindrances imparted by the alkyl substituents in the vicinity of the BTDthiophene linkages. This rationale can also be applied in the present case to explain the differences in the dihedral angles between the thiophene and BTD units.

It has been reported that the intramolecular interaction between chalcogen atoms affects the geometry of molecules, although the origin of this interaction is still not clear [38-42]. For example, it has been reported that the crystal structure of the 3,4-ethylenedioxythiophene dimer, which has oxygen atoms at the $\beta$-position of the thiophene ring similarly to 3-(n-pentyloxy)thiophene, has a planar structure, and that the distance between the sulfur and oxygen atoms is significantly shorter than the

(a)

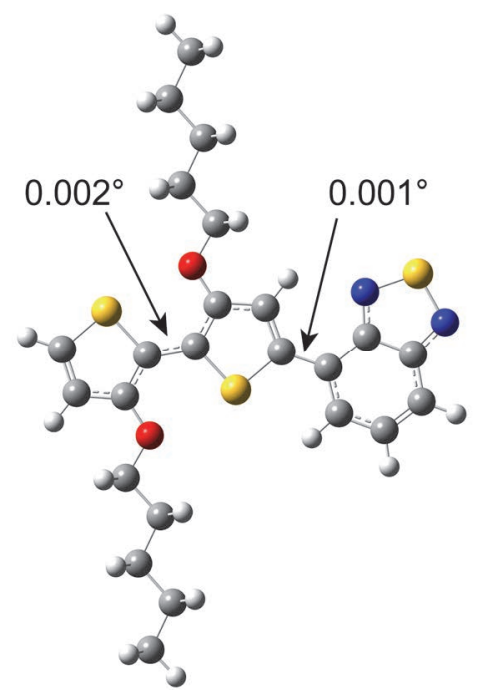

(b)

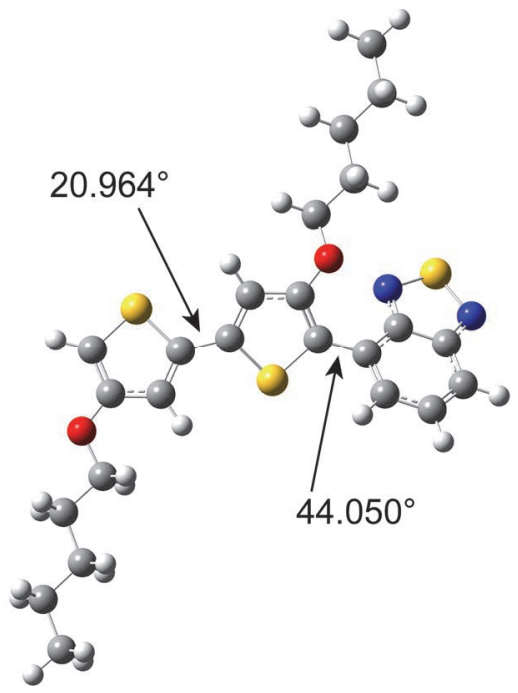

Fig. 4. Optimized molecular geometries for the monomer units of (a) $h \boldsymbol{h} 2 \mathrm{~T}-\mathrm{BTD}$ and (b) tt2T-BTD as calculated using Gaussian 09 at the B3LYP/6-31G(d) level of theory. sum of their van der Waals radii. In the case of hh2T-BTD, the oxygen atoms of the alkoxy groups face the sulfur atoms of the thiophene rings. Consequently, the co-planarity observed between the two thiophene units is maintained by this effect.

Thus, hh2T-BTD exhibits high planarity throughout the entire main chain, allowing the $\pi$ conjugation of $h \boldsymbol{h 2 T}$-BTD to be highly extended. It is this phenomenon that causes the red shift of the absorption wavelength region and the negative shift of the oxidation potential.

\section{Conclusion}

D-A-type polymers having alkoxy-substituted bithiophene D units and BTD-based A units were synthesized. Two polymerization methods, DArP and Stille-type polycondensation, were explored. The DArP method affords polymers with higher molecular weights. The optical absorption band of the polymer with a head-to-head configuration at the bithiophene unit was observed at a higher wavelength than that with a tail-to-tail configuration. Furthermore, the oxidation potential of the head-tohead-type polymer is more negative than that of the tail-to-tail polymer. These differences can be rationalized in terms of a) the steric hindrance between the BTD units and the alkyl substituents and b) the chalcogen interaction between sulfur and oxygen atoms.

\section{Acknowledgements}

This research was supported in part by JSPS KAKENHI Grant Number JP16K05920 and a grant from the SEI Group CSR Foundation (I. I.). The authors are grateful to Dr. Daisuke Kajiya at the Natural Science Center for Basic Research and Development (N-BARD) of Hiroshima University for the NMR spectrometry analysis of the polymer samples. We would like to thank Editage (www.editage.jp) for English language editing.

\section{References}

1. A. J. Heeger, Chem. Soc. Rev., 39 (2010) 2354.

2. P. Bujak, I. Kulszewicz-Bajer, M. Zagorska, V. Maurel, I. Wielgus, and A. Pron, Chem. Soc. Rev., 42 (2013) 8895.

3. T. Marszalek, M. Li, and W. Pisula, Chem. Commun., 52 (2016) 10938.

4. H. A. M. van Mullekom, J. A. J. M. Vekemans, E. E. Havinga, and E. W. Meijer, Mater. Sci. Eng. $R, 32$ (2001) 1.

5. P. M. Beaujuge, C. M. Amb, and J. R. Reynolds, Acc. Chem. Res., 43 (2010) 1396. 
6. X. Lv, W. Li, M. Ouyang, Y. Zhang, D. S. Wright, and C. Zhang, J. Mater. Chem. C, 5 (2017) 12.

7. W. Li and T. Michinobu, J. Photopolym. Sci. Technol., 30 (2017) 495.

8. J. Fabian, Chem. Rev., 92 (1992) 1197.

9. K.-Y. Pu and B. Liu, Biosens. Bioelectron., 24 (2009) 1067.

10. K. Lee, L. K. Povlich, and J. Kim, Analyst, 135 (2010) 2179.

11. L. Cheng, C. Wang, L. Feng, K. Yang, and Z. Liu, Chem. Rev., 114 (2014) 10869.

12. X. Song, Q. Chen, and Z. Liu, Nano Res., 8 (2015) 340.

13. K. Shizu, T. Miwa, Y. Wada, I. Ogata, and H. Kaji, J. Photopolym. Sci. Technol., 30 (2017) 475.

14. Y. Kunugi, S. Murata, H. Otsuki, and K. Okamoto, J. Photopolym. Sci. Technol., 29 (2016) 331.

15. Z.-G. Zhang and J. Wang, J. Mater. Chem., 22 (2012) 4178.

16. C. Liu, K.Wang, X. Gong, and A. J. Heeger, Chem. Soc. Rev., 45 (2016) 4825.

17. H. Benten, D. Mori, H. Ohkita, and S. Ito, $J$. Mater. Chem. A, 4 (2016) 5340.

18. T. Yasuda, J. Kuwabara, L. Han, and T. Kanbara, J. Photopolym. Sci. Technol., 29 (2016) 347.

19. Y. Ie, Y. Kishimoto, K. Morikawa, and Y. Aso, $J$. Photopolym. Sci. Technol., 31 (2018) 145.

20. I. Imae, K. Nawa, Y. Ohsedo, N. Noma, and Y. Shirota, Macromolecules, 30 (1997) 380.

21. I. Imae, D. Tokita, Y. Ooyama, K. Komaguchi, J. Ohshita, and Y. Harima, J. Mater. Chem., 22 (2012) 16407.

22. I. Imae, S. Imabayashi, K. Komaguchi, Z. Tan, Y. Ooyama, and Y. Harima, $R S C A d v$., 4 (2014) 2501.

23. I. Imae, H. Sagawa, T. Mashima, K. Komaguchi, Y. Ooyama, and Y. Harima, Open J. Polym. Chem., 4 (2014) 83.

24. I. Imae, T. Mashima, H. Sagawa, K. Komaguchi, Y. Ooyama, and Y. Harima, J. Solid State Electr., 19 (2015) 71.

25. I. Imae, H. Sagawa, and Y. Harima, Jpn. J. Appl. Phys., 57 (2018) 03EJ01.

26. I. Imae, M. Kumano, and Y. Harima, Sci. $A d v$. Mater., 11 (2019) 792.

27. J. Pommerehne, H. Vestweber, W. Guss, R. F. Mahrt, H. Bässler, M. Porsch, and J. Daub, $A d v$. Mater., 7 (1995) 551.

28. M. A. Keegstra, T. H. A. Peters, and L. Brandsma, Tetrahedron, 48 (1992) 3633.

29. Y. Wang and T. Michinobu, J. Mater. Chem. C,
4 (2016) 6200.

30. P. B. Pati, Org. Electron., 38 (2016) 97.

31. S. E. Tan and M. S. Sarjadi, Polym. Sci. Ser. B Polym. Chem., 59 (2017) 479.

32. M. Li, C. An, W. Pisula, and K. Müllen, Acc. Chem. Res., 51 (2018) 1196.

33. E. Bundgaard and F. C. Krebs, Polym. Bull., 55 (2005) 157.

34. M. Jayakannan, P. A. van Hal, and R. A. J. Janssen, J. Polym. Sci., Part A: Polym. Chem., 40 (2002) 261.

35. P. Ledwon, N. Thomson, E. Angioni, N. J. Findlay, P. J. Skabara, and W. Domagala, $R S C$ Adv., 5 (2015) 77303.

36. C. Doyranlı, B. Çolak, G. Lacinel, M. Can, F. B. Koyuncu, and S. Koyuncu, Polymer, 108 (2017) 423.

37. Gaussian 09, Revision D.01, M. J. Frisch, G. W. Trucks, H. B. Schlegel, G. E. Scuseria, M. A. Robb, J. R. Cheeseman, G. Scalmani, V. Barone, B. Mennucci, G. A. Petersson, H. Nakatsuji, M. Caricato, X. Li, H. P. Hratchian, A. F. Izmaylov, J. Bloino, G. Zheng, J. L. Sonnenberg, M. Hada, M. Ehara, K. Toyota, R. Fukuda, J. Hasegawa, M. Ishida, T. Nakajima, Y. Honda, O. Kitao, H. Nakai, T. Vreven, J. A. Montgomery, Jr., J. E. Peralta, F. Ogliaro, M. Bearpark, J. J. Heyd, E. Brothers, K. N. Kudin, V. N. Staroverov, R. Kobayashi, J. Normand, K. Raghavachari, A. Rendell, J. C. Burant, S. S. Iyengar, J. Tomasi, M. Cossi, N. Rega, J. M. Millam, M. Klene, J. E. Knox, J. B. Cross, V. Bakken, C. Adamo, J. Jaramillo, R. Gomperts, R. E. Stratmann, O. Yazyev, A. J. Austin, R. Cammi, C. Pomelli, J. W. Ochterski, R. L. Martin, K. Morokuma, V. G. Zakrzewski, G. A. Voth, P. Salvador, J. J. Dannenberg, S. Dapprich, A. D. Daniels, Ö. Farkas, J. B. Foresman, J. V. Ortiz, J. Cioslowski and D. J. Fox, Gaussian, Inc., Wallingford CT, 2009.

38. J.-M. Raimundo, P. Blanchard, P. Frère, N. Mercier, I. Ledoux-Rak, R. Hierle, and J. Roncali, Tetrahedron Lett., 42 (2001) 1507.

39. P. Leriche, M. Turbiez, V. Monroche, P. Frère, P. Blanchard, P. J. Skabara, and J. Roncali, Tetrahedron Lett., 44 (2003) 649.

40. S. S. Zade, S. Panda, H. B. Singh, R. B. Sunoj, and R. J. Butcher, J. Org. Chem., 70 (2005) 3693.

41. D. Roy and R. B. Sunoj, J. Phys. Chem. A, 110 (2006) 5942.

42. T. Ozaki, A. Nomoto, and A. Ogawa, Heteroatom. Chem., 22 (2011) 579. 